\title{
Determination of Free Fatty Acids in Palm Oil Samples by Non-Aqueous Flow Injection Using Salicyaldehyde-2,4-Dinitrophenylhydrazone as Colorimetric Reagent
}

\author{
Abdussalam Salhin Mohamed Ali ${ }^{1{ }^{1 *}}$, Abdurrhman Moussa Abdurrhman ${ }^{2}$ \\ ${ }^{1}$ School of Chemical Science, Universiti Sains Malalysia, 11800, Penang, Malaysia \\ ${ }^{2}$ Chemistry Department, Faculty of Science, Sirt University, Sirt, PO. 674, Libya \\ *Corresponding Author: salam_salhin@yahoo.com
}

Copyright (C) 2013 Horizon Research Publishing All rights reserved.

\begin{abstract}
The free fatty acids (FFA) in palm oil were determined by flow injection titrimetric method using salicyladhyde-2,4-dinitrophenylphenylhydrazone (SDPH) as a new coloring reagent. The compound was synthesized and its structure was established using different spectroscopic data. It exhibited sensitive colour changes in basic medium and absorb at $482 \mathrm{~nm}$. Single-line manifold using SDPH as indicator was developed. Flow injection operating parameters such as carrier, reagent concentration, flow rate, size of mixing chamber and injection volume were optimized. The method is recommended for the determination of oil samples with acidity degree (a.d.) higher than 0.5 a.d. Twelve oil samples were tested using the appropriate FIA manifold and the obtained results were compared to the standard PORIM method. Good correlation $\left(r^{2}=0.99\right)$ between the two methods was obtained
\end{abstract}

Keywords Palm oil, FIA analysis, Free Fatty Acid, Hydrazone.

\section{Introduction}

Palm oil is one of the major oils and fats produced and traded in the world today. Within the span of four decades, palm oil has emerged as the fastest growing oil in the world. Currently, most of the world's production of palm oil comes from south-east Asia, in particular Malaysia and Indonesia. Malaysia is one of the largest producers in the world [1], accounting for $32.7 \%$ of the world oils and fats production in 2011 [2]. To meet the ever changing needs and for the industry to remain competitive, innovations in many forms are necessary. The major fatty acids (FFA) in palm oil are myristic, palmitic, stearic, oleic and linoleic. The minor constituents can be divided into two groups. The first group consists of fatty acid derivatives, such as partial glycerides (mono- and diacyl glycerols), phosphatides, esters and sterols. The second group includes classes of compounds not related chemically to fatty acids called nonglyceride constituents. The non-glyceride fraction of palm oil consists of sterols, triterpene alcohols, tocopherols, phospholipids, chlorophylls, carotenoids volatile flavour components such as aldehydes and ketones. There are also some hydrocarbons, aliphatic alcohols, free sterols, tocopherols, pigments, partial glycerides and phosphatides, and trace metals [3].

FFA content is one of the most frequently determined quality indices during edible oils production, storage and marketing. It is a measure of the extent to which hydrolysis has liberated fatty acids from their ester linkage with the parent triglyceride molecule [4]. Edible oils undergo various processing steps, resulting in low FFA content [5]. Palmitic acid is the major saturated fatty acid in palm oil and this balanced by almost $39 \%$ monounsaturated oleic acid and $11 \%$ polyunsaturated linoleic acid. The remainder is largely stearic acid (5\%) and myristic acid (1\%). Palm oil has saturated and unsaturated fatty acids in approximately equal amounts [3]. Linoleic acid and palmitic acid are usually used as indicators to measure the extent of fat deterioration because linoleic acid is more susceptible to oxidation whereas palmitic acid is more stable to oxidation [6].

There are many analytical methods used for FFA determination such as the manual titration official method, standard method based on the PORIM method [7], capillary gas chromatography, and to a lesser extent, HPLC and capillary electrophoresis (CE), where the analyte is first isolated using liquid-liquid extraction or solid-phase extraction prior to the analytical separation. Derivatization methods are necessary for these methods either to increase the volatility of analytes or to improve the sensitivity as in HPLC and CE methods [8]. Accordingly, several papers have been published for the determination of FFA in 
biological fluids [9,10], milk [11], fruit juices [12] and oil and fats [13-16]. Some of the methods used for the determination of oil acidity are potentiometry [17], sequential injection analysis using lab-onvalve system [4], biosensors based either on purified enzymes $[18,19]$ or intact enzymes (e.g. butyrate kinase from E. coli) in bacteria [20].

The above mentioned approaches, although interesting, are plagued by several problems, such as short lifetime, long response times and frequently poisoned by sample components. Accordingly, alternative analytical methods for the determination of palm oil quality parameters have been developed. An FTIR method for the determination of FFA in olive oil, fats and oils by measuring the carbonyl group $(\mathrm{C}=\mathrm{O})$ band at $1711 \mathrm{~cm}^{-1}$ have been reported [15]. Although this method does not require solvents and short analysis time (2 min), it was not considered due to the higher cost in the instrumentation involved. Therefore, it was the interest of our group is to find an alternative analytical method for the determination of palm oil quality parameters. In our approach, low cost and one that can potentially be adopted for process control are given special consideration. Flow injection analysis (FIA) methods, in combination with suitable flow through detectors seem more attractive as they can be easily automated and are able to meet the objectives outlined above.

However, a few reports on the FIA determination of FFA in food samples were reported. The earlier FIA methods contain undesirable features such as involving on-line extractions uses toxic organic solvents, complex flow lines (multiple channels), and involving phase separators. A single- and two-line manifolds were developed using phenolphthalein (PHT) and bromothymol blue (BTB) as indicators [8]. Another alternative two-line manifold non-aqueous titimetric method for the determination of palm oil acidity was also developed using N'-(2,4-dinitrophenyle)acetohydrazide (NDA) as indicator [4]. The present study is developed based on the synthesized hydrazone reagent that exhibits colour change between acidic and basic medium using two-line manifold FIA method. Therefore, the synthesized compound will be applied as indicator for the determination of FFA in palm oil. The present method offered an interesting alternative method for the determination of various types of palm oil samples

\section{Experimental}<smiles>NNc1ccc([N+](=O)[O-])cc1[N+](=O)[O-]</smiles>

(1)

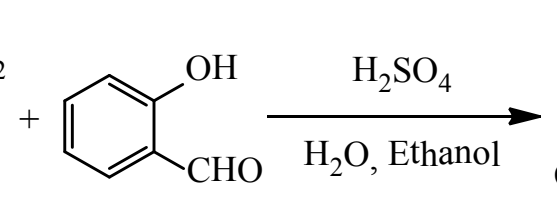

(2)

\subsection{Instruments}

A Hitachi U-2000 double beam spectrophotometer was used to obtain UV spectra of the new reagent and palm oil in 1-propanol. A Hitachi U-1000 spectrophotometer was used for FIA analysis. Fourier transfer infrared analysis was performed using a Perkin Elmer 2000 FT-IR spectrophotometer. The ${ }^{1}$ HNMR spectra were recorded at $25^{\circ} \mathrm{C}$ using a Bruker $400 \mathrm{MHz}$ spectrophotometer.

\subsection{Chemicals}

2,4-Dinitrophenylhadrazine, 98\% (Aldrich), 1-propanol and ethanol (SYSTERM)), potassium hydroxide ( $R$ \& $M$ Chemicals), phenolphthalein (Ajax Chemicals), palmitic acid, 99\% (BDH Chemicals), and salicylaldehyde (Fluka).

\subsection{Synthesis of \\ salicylaldehyde-2,4-dinitrophenylhydrozone (SDPH)}

The present compound (SDPH) was prepared according to the reported method given in the literature [21-24]. A 2,4-dinitrophenyl hydrazine (1) $(1.56 \mathrm{~g}, 10 \mathrm{mmol})$ was dissolved in $4 \mathrm{~mL}$ of concentrated sulfuric acid followed by addition of $20 \mathrm{~mL}$ distilled water and $50 \mathrm{~mL}$ ethanol. The mixture was thoroughly mixed and filtered if necessary. An aquimolar (1.4 g, $10 \mathrm{mmol})$ salicylaldehyde (2) in $10 \mathrm{~mL}$ ethanol was added dropwise to the above solution with continuous stirring. An orange-yellow precipitate was formed almost immediately. The precipitate was filtered, washed with cold ethanol and dried in the oven at $60^{\circ} \mathrm{C}$. Yield: $97 \%$. The synthetic route of the preparation of dye compound (SDPH) is depicted in Figure 1.

\subsection{Carrier solutions}

Stock carrier stream solutions was prepared by weighing $0.28 \mathrm{~g}(10 \mathrm{mmol}) \mathrm{KOH}$ and dissolved in $30 \mathrm{~mL}$ 1-propanol in $50 \mathrm{~mL}$ volumetric flask. The solution was first sonicated for 15 minutes and then diluted to the mark with 1-propanol, and then calibrated following a reported procedure [8]. A one mmol SDPH was prepared by dissolving $0.31 \mathrm{~g}$ of the dye compound in 1 liter 1-propanol after sonication for 15 minutes. Carrier solution containing a mixture of $1.0 \times 10^{-3}$ $\mathrm{M} \mathrm{KOH}$ and $1.5 \times 10^{-4} \mathrm{M} \mathrm{SDPH}$ was prepared daily by diluting from the stock solutions of both.

\footnotetext{
Figure 1. The synthetic route of SDPH.
} 


\subsection{Sample preparation}

\subsubsection{Stock oil $\left(100 \mathrm{~g} \mathrm{~L}^{-1}\right)$ Samples}

Cooking oil (Vesawit, Yen Lee Edible Oils Sdn. Bhd) was purchased from local supermarket. Its acidity degree was tested before the preparation of stock solution. A stock sample was prepared by dissolving $25 \mathrm{~g}$ oil in $50 \mathrm{~mL}$ 1-propanol. This sample was used to prepare stock and standard palmatic acid solutions.

\subsubsection{Stock Palmitic Acid Solution, 100 a.d}

A $5.0 \mathrm{~g}$ palmitic acid was weighed in and dissolved in 50 $\mathrm{mL}$ stock oil solution prepared above. The solution was sonicated for 20 minutes and made up to the mark with stock oil, and stored at room temperature. This solution was used to prepare working calibration curve samples. Table 1 presents the standard solutions used for the preparation of the calibration curve of palmitic acid.

Table 1. Preparation of standard solutions of palmitic acid

\begin{tabular}{|c|c|c|}
\hline $\begin{array}{c}\text { Concentration } \\
\text { required, a.d. }\end{array}$ & $\begin{array}{c}\text { Volume of stock } \\
\text { palmitic acid, } \mathrm{mL}\end{array}$ & $\begin{array}{c}\text { Volume of stock oil, } \\
\mathrm{mL}\end{array}$ \\
\hline 0.5 & 0.05 & 9.95 \\
\hline 1.0 & 0.10 & 9.90 \\
\hline 2.0 & 0.20 & 9.80 \\
\hline 5.0 & 0.50 & 9.50 \\
\hline 10.0 & 1.00 & 9.00 \\
\hline 20.0 & 2.00 & 8.00 \\
\hline 40.0 & 4.00 & 6.00 \\
\hline 80.0 & 8.00 & 2.00 \\
\hline 100.0 & 10.00 & 0.00 \\
\hline
\end{tabular}

\subsubsection{Palm Oil Samples}

Samples were prepared following reported procedure with modifications $[8,15]$. Palm oil samples were firstly neutralized and then extracted four times with $0.01 \mathrm{M} \mathrm{KOH}$ in a separating funnel to remove all FFAs. The aqueous layer was removed and the resulted neutralized oil was centrifuged for 60 minutes at $3600 \mathrm{rpm}$. Samples that were used in the study consisted of RBD palm oil, RBD kernel palm kernel oil, crude palm oil and RBD palm stearin. All samples were heated to $60-70^{\circ} \mathrm{C}$ for homogenization before sampling. For refine oils (liquid form), 10 grams of sample was diluted to $50 \mathrm{~mL}$ with 1-propanol. For oil samples that have solid fraction (crude palm oil and streain), free fatty acids were extracted as follow: 10 grams of heated oil samples was weighed and diluted with $25 \mathrm{~mL}$ of 1-propanol when sample was still hot. The sample was then stirred and allowed to cool and crystallized, filtered and washed with $10 \mathrm{~mL}$ 1-propanol. Finally, the filtrate was collected and top up to the $50 \mathrm{~mL}$ mark with 1-propanol.

\subsubsection{Manual Titrimetry (Standard Method)}

Palm oil samples were determined for their acidity degree using the official method [8]. The free acids are frequently expressed in terms of acid value. The acid value is defined as number of milligram of $\mathrm{KOH}$ necessary to neutralize $1.0 \mathrm{~g}$ of the sample. Sample was weighed according to the expected acidity and diluted with neutralized 1-propanol to the $50 \mathrm{~mL}$ mark. The sample was transferred into $250 \mathrm{~mL}$ conical flask, followed by the addition $0.5 \quad \mathrm{~mL} \quad 1.0 \quad \% \quad(\mathrm{w} / \mathrm{v})$ phenolphthalein in 1-propanol. The sample was then titrated against $0.1 \mathrm{M} \mathrm{KOH}$ till the first pink colour appears and was persistent for 30 seconds.

\subsection{FIA Setup and Procedure}

The flow injection manifold used in this study is depicted in Figure 2. It consists of a Gilson Miniplus 3 peristaltic pump, UV-Vis spectrophotometer equipped with an Unonic ultramicroflow cell $(20 \mu \mathrm{L}$ and $1.0 \mathrm{~mm}$ path length), mixing chamber [8], a Rheodyne type 500 rotary injection valve and recorder. The FIA procedure is the same for both standards and samples. The oil is directly injected $(0.5 \mathrm{~mL})$ into the stream. In the mixing chamber, it reacted with the carrier, increasing the acidity along the sample zone and changing the colour from red to yellow. Therefore, a negative absorbance peak, which has a linear relationship with the logarithm of the acidity of the sample as reported by Saad et al., [8] and Karlberg and Pacey [25] was recorded.

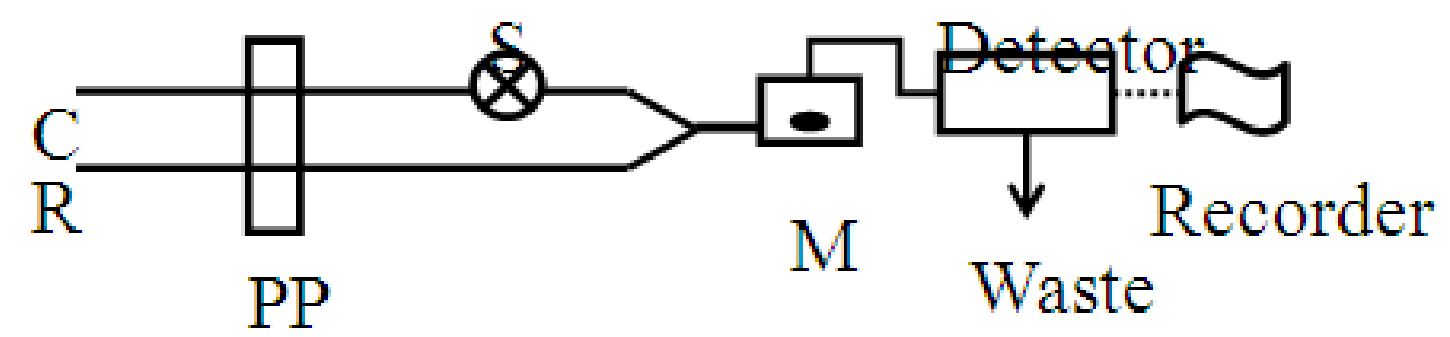

$\mathrm{C}$

Figure 2. Two-line FIA manifold. C, Carrier stream; R, reagent system; S, Sample injector; PP, peristaltic pump; MC, Mixing chamber; and W, Waste. 


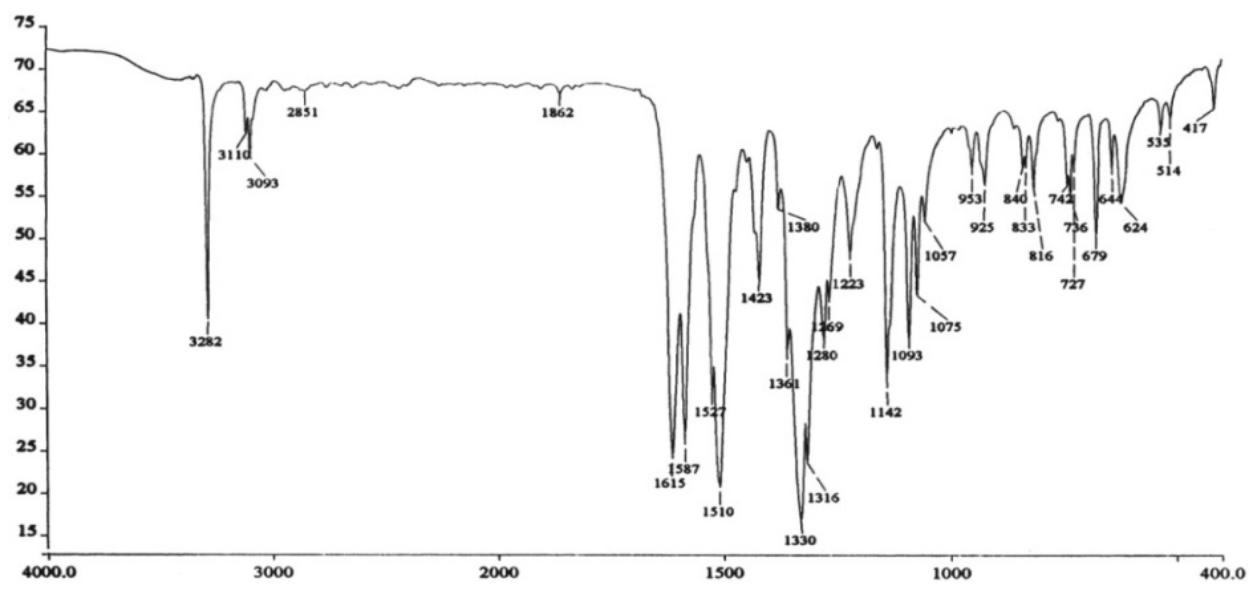

Figure 3. FTIR spectra of salicylaldehyde-2,4-dinitrophenylhydrazone (SAPH).

\section{Result and Discussion}

\subsection{Characterization of SDPH}

IR analysis: The IR measurements were recorded over the range 4000-400 $\mathrm{cm}^{-1}$. The IR spectrum of SDPH (Figure 3) shows a strong shift in the absorption peaks compared with the free DNPH as reported by Chis et al., [26]. $\mathrm{C}=\mathrm{N}$ (stretching) was assigned at $1615 \mathrm{~cm}^{-1} \cdot v=3326 \mathrm{~cm}^{-1}(\mathrm{br}$, $\mathrm{NH}), 3282$ (m, OH), 3101 (w), 1512 (s, NO $)_{2}, 1419$ (m), 1334 (s, NO $)_{2}, 1273$ (vs, C-O), 1142 (s), 833 (w), 764 (w), $578(\mathrm{~m}) \mathrm{cm}^{-1}$. Nitro groups vibrations are shifted to 1587-1423 and 1380-1330 $\mathrm{cm}^{-1}$, respectively. Hydrogen bonding has little effect on the $\mathrm{NO}_{2}$ asymmetric stretching vibrations. The bands at 1609, 1571 and $1371 \mathrm{~cm}^{-1}$ for SDPH are corresponded to asymmetric and symmetric stretching of $\mathrm{NO}_{2}$ group, respectively

NMR analysis: The ${ }^{1} \mathrm{HNMR}$ spectrum (prepared in DMSO) of the SDPH displayed 10 signals, at $10.02 \mathrm{ppm}(-\mathrm{NH}, \mathrm{s})$, 6.94 (ArH, t), 7.19 (ArH, s), 7.24 (ArH, d), 7.34 (ArH, t), 7.61 (ArH, d), 8.25, (ArH, s), 8.36 (ArH, q), 9.13 (ArH, d), $10.02(\mathrm{H}, \mathrm{s})$ and $11.29(\mathrm{H}, \mathrm{s})$.

Table 2. Characteristics of solvents studied as FIA carrier stream.

\begin{tabular}{|c|c|c|c|}
\hline \multirow{2}{*}{ Solvents } & \multicolumn{3}{|c|}{ Solubility } \\
\cline { 2 - 4 } & SDPH & KOH & palm oil \\
\hline Water & Insoluble & Soluble & Insoluble \\
\hline Methanol & Moderate & Moderate & Insoluble \\
\hline Ethanol & Low & Soluble & Insoluble \\
\hline Acetone & Soluble & Moderate & Soluble \\
\hline 1-propanol & Soluble & Soluble & Soluble \\
\hline THF & Insoluble & Insoluble & Soluble \\
\hline 2-propanol & Moderate & Soluble & Soluble \\
\hline DMSO & Soluble & Soluble & Soluble \\
\hline
\end{tabular}

\subsection{Choice of Solvent}

This information is vital because a suitable solvent has to be chosen to dissolve the indicator, $\mathrm{KOH}$, and palm oil as well to be used as the FIA carrier stream. The characteristics of the eight solvents studied are summarized in Table 2. Data showed that only DMSO and 1-propanol were able to dissolve all components (SDPH, $\mathrm{KOH}$, palm oil). Therefore, 1-propanol was chosen for further studies, because of it is non-volatile and cheaper.

\subsection{UV Characteristics}

SDPH react rapidly in 1-propanol with $\mathrm{KOH}$, forming intensively coloured red-brownish product. The maximum absorption takes place at $482 \mathrm{~nm}$ (Figure 4). Oil samples containing free fatty acid is directly injected (without dilution) into the carrier stream with 1-propanol as carrier solution contained potassium hydroxide as titrant and SDPH as indictor. In the mixing chamber, the sample mixes and reacts with the carrier stream, increasing the acidity along the sample zone and changing the colour of the SDPH from red-brownish to yellow.

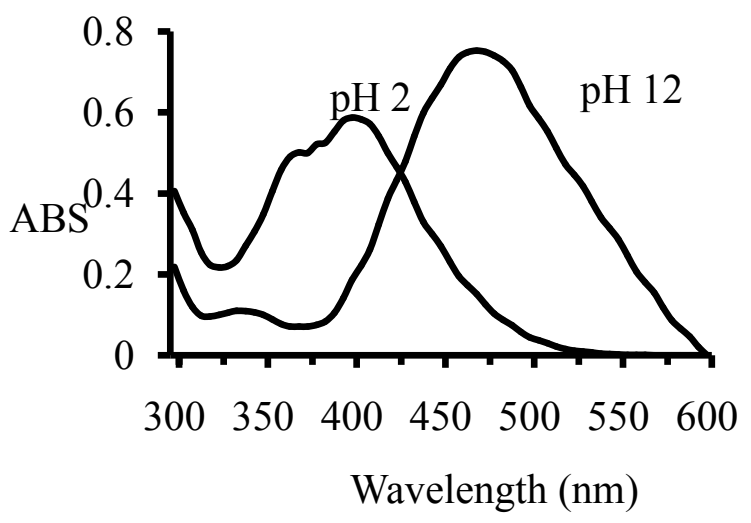

Figure 4. UV-Vis absorption spectra of SDPH $\left(1.5 \times 10^{-4} \mathrm{M}\right)$ in 1-propanol at different $\mathrm{pH}$

A spectrophotometer set at $\lambda \max =482 \mathrm{~nm}$ was used to monitor continuously the decrease of reagent absorbance and the FIA titration peak formed. The area of the peak ( $\Delta$ Abs vs. time) is linearly correlated with the logarithm of the 
sample acidity [25]. The calculation of peak area (instead of peak height), enables a larger range of linearity between the value measured (the peak area) and the logarithm of sample acidity [27].

\subsection{FIA Method Development Using Two-Line Manifold}

A two-line manifold designed (Figure 2) for direct injection of sample into a carrier stream without prior dilution with the 1-propanol as carrier was investigated. The injection sample was merged with carrier stream, mixed in the mixing chamber, before finally passing through the flow cell of the spectrophotometer. The mixing chamber allowed the mixing of oil sample with 1-propanol before neutralized by $\mathrm{KOH}$. Without the mixing chamber, peaks of poor reproducibility were obtained. Several parameters that affect the FIA signal were investigated. These include sample loop, mixing chamber, flow rate and carrier and reagent concentrations.

\subsubsection{Effect of Flow Rate}

The effect of flow rate was tested by adjusting the peristaltic pump to different flow rates of 3.8, 4.0, 4.8, 5.0, 5.5, 6.6 and $7.5 \mathrm{~mL} \mathrm{~min}^{-1}$. The concentration of $\mathrm{KOH}$ and SDPH were $1.0 \times 10^{-3} \mathrm{M}$ and $1.5 \times 10^{-4} \mathrm{M}$, respectively. It was found that at lower flow rate, the FIA signal tends to have a wider peak and peak shape tends to be asymmetry. Analysis time was found to be increased and thus consumed more solvent. However, as the flow rate continued to be increased, the produced FIA signal showed sharper peaks, making it difficult to integrate its area. However, increasing the flow rate of carrier stream from 3.8 to $7.5 \mathrm{~mL} \mathrm{~min}$ decreased the width of the FIA signal till a point when the peak was most satisfactory. When the flow rate was further increased, the peak width decreased slightly till a plateau was reached as shown in Figure 5. The choice of flow rate was a compromise between sample throughput and sensitivity. Flow rate of $4.8 \mathrm{~mL} \mathrm{~min}^{-1}$ was then chosen.

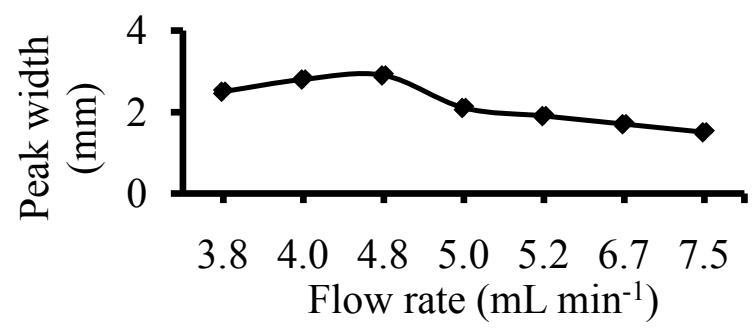

Figure 5. Effect of flow rate of carrier stream on FIA peak width with injection volume $70 \mu \mathrm{L}$

\subsubsection{Effect of $\mathrm{KOH}$ Concentration}

The effect of $\mathrm{KOH}$ concentration was studied by varying its concentration from $6.0 \times 10^{-4} \mathrm{M}$ to $4.0 \times 10^{-3} \mathrm{M}$. The concentration of SDPH was fixed at $1.5 \times 10^{-4} \mathrm{M}$. A $4.0 \mathrm{~mL}$ mixing chamber and $70 \mu \mathrm{L}$ injection volumes with a flow rate of $4.8 \mathrm{~mL} \mathrm{~min}{ }^{-1}$ were used. The peak area becomes smaller while the $\mathrm{KOH}$ concentration increased from $6.0 \times$
$10^{-4} \mathrm{M}$ to $4.0 \times 10^{-3} \mathrm{M}$ (Figure 6). The suitable $\mathrm{KOH}$ concentration was $1.0 \times 10^{-3} \mathrm{M}$ as larger peak area was obtained.

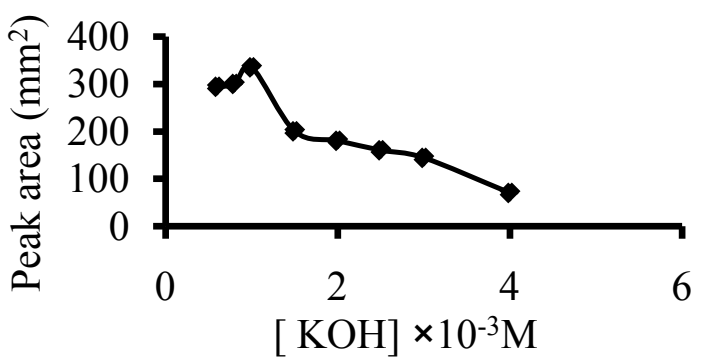

Figure 6. The effect of $\mathrm{KOH}$ concentration on peak area.

\subsubsection{Effect of SDPH Concentration}

The effect of the SDPH concentration on the peak area was also investigated. In this study, the $\mathrm{KOH}$ concentration was fixed at $1.0 \times 10^{-3} \mathrm{M}$ as well other parameters while SDPH concentration was varied from $2.0 \times 10^{-4} \mathrm{M}$ to $6.0 \times$ $10^{-5} \mathrm{M}$. SDPH concentration of $1.5 \times 10^{-4} \mathrm{M}$ gives the highest peak area (Figure7). The peak shape becomes smaller when concentration is increased.

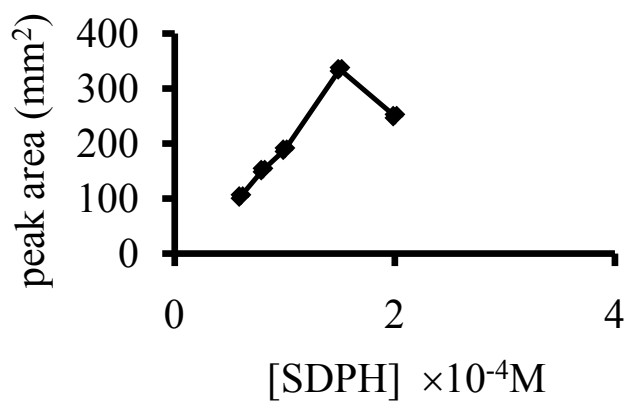

Figure 7. Effect of SDPH concentration on the peak area.

\subsubsection{Effect of Injection Volume}

The effect of injection volume was studied using injection loops of 10 to $125 \mu \mathrm{L}$. A flow rate of $4.8 \mathrm{~mL} \mathrm{~min}^{-1}$ was used. Tailing peaks when $125 \mu \mathrm{L}$ of injection volume was used were obtained. The injection volume poses some effect on the sensitivity of the system due to dispersion of sample in carrier stream and thus sample volume of $70 \mu \mathrm{L}$ was used.

\subsubsection{Effect of Mixing Chamber}

The present FIA titration system is based on peak width measurement. Therefore, large dispersion can be obtained by means of a mixing chamber. The effect of mixing chamber was studied by varying the size of mixing chamber from 1.0 to $6.0 \mathrm{~mL}$. At fixed concentrations of $\mathrm{KOH}\left(1.0 \times 10^{-3} \mathrm{M}\right)$ and $\operatorname{SDPH}\left(1.5 \times 10^{-4} \mathrm{M}\right)$, injection volume $(70 \mu \mathrm{L})$ and flow-rate $\left(4.8 \mathrm{~mL} \mathrm{~min}^{-1}\right)$, the peak area was increased with the increase of the size of mixing chamber (Figure 8). Therefore, $4.0 \mathrm{~mL}$ size of mixing chamber was chosen. 


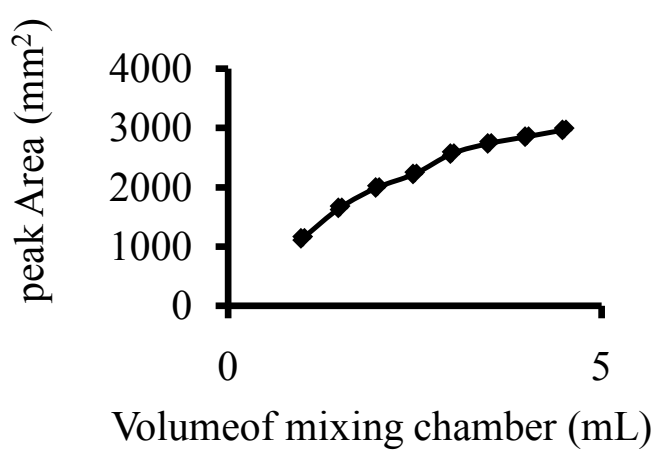

Figure 8. Effect of mixing chamber on peak area.

\subsubsection{Adopted Parameter}

The adopted FIA conditions for the two-line manifold employing the new indicator (SDPH) are summarized in Table 3. The sample volume needed in this system is smaller $(70 \mu \mathrm{l})$, when compared to previous work done by Nourous et al., [28] (175 $\mu \mathrm{L})$ and Mariotti and Mascini (2001) (280 $\mu \mathrm{L})$ using phenolphthalein (PHT) as indicator. The mixing chamber used was found four times larger than that used by Saad et al., [8] and Teoh [4] on their FIA studies using PHT and NDA as indicators, respectively.

Table 3. Comparison between FIA condition used for two-line manifold employing SDPH, PHT, BTB and NDA as indicators.

\begin{tabular}{|c|c|c|c|c|}
\hline Parameters & SDPH & PHT & BTB & NDA \\
\hline KOH concentration /M & $1 \times 10^{-3}$ & $\begin{array}{c}5.0 \times 10 \\
-4\end{array}$ & $2.5 \times 10^{-4}$ & $\begin{array}{c}5.0 \times 10 \\
-5\end{array}$ \\
\hline Indicator concentration /M & $\begin{array}{c}1.5 \times 10 \\
-4\end{array}$ & $\begin{array}{c}2.5 \times 10 \\
-5\end{array}$ & $2.5 \times 10^{-5}$ & $\begin{array}{c}1.4 \times 10 \\
-5\end{array}$ \\
\hline $\begin{array}{c}\text { Volume of mixing chamber } \\
(\mathrm{mL})\end{array}$ & 4.0 & 1.0 & 1.0 & 1.0 \\
\hline $\begin{array}{c}\text { Injection volume / } \mu \mathrm{L} \\
\text { Flow rate / mL min }{ }^{-1}\end{array}$ & 70 & 25 & 25 & 25 \\
\hline $\begin{array}{c}\text { Reagent consumption per } \\
\text { sample/mL }\end{array}$ & $\begin{array}{c}3.75 \\
-7.5\end{array}$ & $\begin{array}{c}6.0-16.2 \\
0\end{array}$ & $\begin{array}{c}11.0-16 \\
.0\end{array}$ & $\begin{array}{c}6.8 \\
-13.6\end{array}$ \\
\hline Detection wavelength/nm & 482 & 562 & 627 & 435 \\
\hline Reference & $\begin{array}{c}\text { Presen } \\
\mathrm{t} \text { work }\end{array}$ & {$[8]$} & {$[8]$} & {$[4]$} \\
\hline
\end{tabular}

Table 3 shows a comparison between the FIA conditions applied for two-line manifold using SDPH, PHT, BTB and NDA as indicators for the determination of FFA. The solvent consumption in FIA is always less than the normal titration method, which consumes approximately $50 \mathrm{~mL}$ of solvent in an analysis. Therefore, even though the present method exhibits lesser sensitivity (higher detection limit, 0.5 a.d.) it still has the larger linear range $(0.5-100$ a.d. $)$ when compared to the other studies.

\subsection{Calibration}

A calibration curve was obtained for the present FIA system (Figure 9). The line was linear from 0.5-100 a.d. The correlation coefficients, y-intercepts, and slopes of the calibration curve were also obtained. The calibration equation is $\mathrm{y}=413.1 \mathrm{x}+26.655$ with $\mathrm{r}^{2}=0.9908$

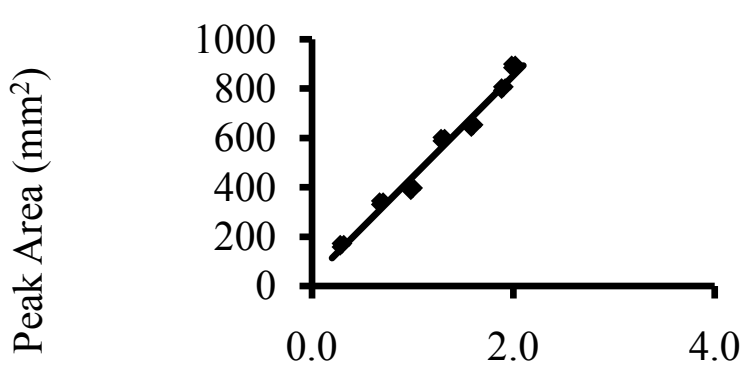

Log.[palmaitic acid], a.d.

Figure 9. Calibration curve for different concentration of standard palmitic acid using SDPH under the optimum conditions (Table 3)

\subsection{Analysis of Real Samples (Palm Oil)}

Twelve palm oil samples were tested. Results obtained were compared to the results obtained by the PORIM standard method which involves manual titration. Results obtained for the twelve samples are shown in Table 4. The correlation of the FIA method with the standard PORIM method is show in Figure 10, where good correlation was found between the two methods. The good correlation showed the proposed method is applicable for palm oil samples.

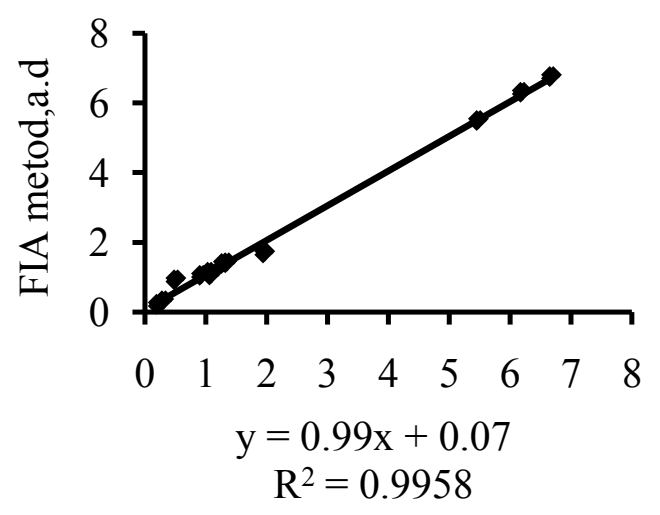

PROIM method, a.d

Figure 10. Correlation between FIA and standard PORIM methods. 
Table 4. Determination of FFA in 12 palm oil samples

\begin{tabular}{|c|l|c|c|}
\hline \multirow{2}{*}{ Sample No. } & \multicolumn{2}{|c|}{ Sample Type } & \multicolumn{2}{|c|}{ Palm oil acidity (FFA content, a.d.) } \\
\cline { 3 - 4 } & & PORIM Official method & Present method \\
\hline 1 & RBD palm oil & $0.52(0.21)$ & $0.93(0.13)$ \\
\hline 2 & RBD palm oil & $0.31(0.01)$ & $0.43(0.22)$ \\
\hline 3 & RBD palm oil & $0.22(0.11)$ & $0.23(0.23)$ \\
\hline 4 & RBD palm stearin & $0.93(0.06)$ & $1.06(0.01)$ \\
\hline 5 & RBD palm stearin & $1.06(0.02)$ & $1.15(0.02)$ \\
\hline 6 & RBD palm stearin & $1.09(0.38)$ & $1.07(0.08)$ \\
\hline 7 & RBD palm kernel oil & $1.28(0.07)$ & $1.40(0.38)$ \\
\hline 8 & RBD palm kernel oil & $1.97(0.02)$ & $1.79(0.05)$ \\
\hline 9 & RBD palm kernel oil & $1.35(0.41)$ & $1.42(0.06)$ \\
\hline 10 & Crude palm oil & $6.68(0.61)$ & $6.76(0.03)$ \\
\hline 11 & Crude palm oil & $5.48(0.18)$ & $5.60(0.09)$ \\
\hline 12 & Crude palm oil & $6.20(0.21)$ & $6.31(0.17)$ \\
\hline
\end{tabular}

The values in parenthesis are the standard deviation $( \pm \mathrm{SD})$ data

\section{Conclusion}

A simple, FIA method for the determination of FFA in palm oil samples using two lines FIA manifold employing SDPH hydrazone has been developed. The two-line manifold requires direct injection of oil samples resulting in good sample throughput, and consumes lesser amounts of reagent. The two-line manifold using SDPH as indicator is recommended for the determination of sample with FFA ( $>0.5$ a.d.). The FIA method is found suitable for higher acidity samples (such as Crude RBD palm). Good correlation between the present method and the official methods applied for the determination of FFA in palm oil samples.

\section{Acknowledgments}

We thank the Universiti Sains Malaysia for the RU grant 1001/PKIMIA/811196. A.M. Abdurrhman thanks Sirt University and the Government of Libya for financial support.

\section{REFERENCES}

[1] F. Suliaman and N. Abdullah. Optimum conditions for maximizing pyolysis liquids of oil palm empty fruit bunches. Energy, 36(5), 2352-2359. 2011.

[2] Economics \& Industry Development Division. Malaysia Palm Board. Online available from http://bepi.mpob.gov.my/index.php/summary/521-summary2012.html.

[3] R. Sambanthamurthi, K. Sundram and Y. A. Tan. Chemistry and biochemistry of palm oil. Progress in lipid research. 39 . 507-558. 2000.
[4] B. S. Teoh, Non-aqueous flow injection titrimrtric method using N'-(2, 4-dinitrophenyl)acetohydrazide for The determination of free fatty acids in palm oil samples. MSc.Thesis,Universiti Sains Malaysia. 2006.

[5] D. C. Tandy, W. J. and McPherson. Physical refining of edible oil. Journal of the American Oil Chemistry' Society. 61. 1253-1258. 1984.

[6] H. L. Gan, C. P. Tan, , Y. B. Che Man, I. NorAini, and S. A. H. Nazimah. Monitoring the storage stability of RBD palm olein using the electronic nose. Food Chemistry. 89. 271-282. 2005.

[7] PORIM Test Methods. Palm Oil Research Institute of Malaysia (PORIM), Kuala Lumpur. 1995.

[8] B. Saad, W.L. Cheng, T.W. Wan, and P. L. Boey. Non-aqueous FIA titrimetric determination of FFA in palm oil samples. Journal of food chemistry. 102, 1407-1414. 2006.

[9] [9]. P. Husek, P. Simek, and E. Tvrzicka. Simple and rapid procedure for the determination of individual free fatty acids in serum. Analytica Chimica Acta. 465. 433-439. 2002.

[10] [10]. H. Miwa. High-performance liquid chromatographic determination of free fatty acids and esterified fatty acids in biological materials as their 2-nitrophenylhydrazides. Analytica Chimica Acta. 465. 237-255. 2002.

[11] [11]. Y. Shahin, L. F. Hamzawi, and H. F. Haggag. Fatty acid composition of fat globule membrane neutral lipids from Egyptian buffalo, goat and cow's milk. Food Chemistry. 24. 11-19. 1987.

[12] [12]. J. Jakmunee, L. Pathimapomlert, S. K. Hardwell, and K. Grudpan. Novel approach for non-segmented flow micro-titration with sequential injection using a lab-on-valve system: a model study for the assay of acidity in fruit juices. Analyst. 130. 299-303. 2005.

[13] [13]. J. S. Canham, and G. E. Pacey. Automated free fatty acid determination using flow injection analysis solvent extraction. Journal of American Oil Chemists Society. 64. 1004-1007. 1987. 
[14] L. G. Ekstrom. Automatized method for determination of free fatty acid. Journal of American Oil Chemists Society. 58. 935-938. 1981.

[15] A. A. Ismail, F. R. Van de Voort, G. Emo, and J. Sedman. Rapid quantitative determination of free fatty acid in fats and oils by Fourier Transform Infrared Spectroscopy. Journal of American Oil Chemists Society. 70. 335-341. 1993.

[16] D. Y. Kwon, and J. S. Rhee. A simple and rapid colorimetric method for determination of free fatty acid for lipase assay. Journal of American Oil Chemists Society. 63. 89-92. 1986.

[17] I. Kuselman, Y. I. Tur'yan, T. Burenko, I. Goldfeld, and B. Anisimov, $\mathrm{pH}$-metric determination of acid values in oilseeds without titration. Talanta. 49. 629-637. 1999.

[18] M. Schoemaker, R. Feldbrugge, B. Grundig, and F. Spener. The lipoxygenase sensor, a new approach in essential fatty acid determination in foods. Biosensors and Bioelectronics. 12. 1089-1099. 1997.

[19] F. Schooner, R. E. Simard, and S. Pandian. Colorimetric assay for free fatty acids in butter using flow-injection and immobilized enzymes. Journal of Food Science. 56. 1229-1232. 1991.

[20] A. Schmidt, C. Standfuz-Gabisch, and U. Bilitewski. Microbial biosensor for free fatty acids using an oxygen electrode based on thick film technology. Biosensors and Bioelectronics. 11. 1139-1145. 1996.

[21] A. Vogel. Vogel's Textbook of practical organic chemistry. 4th ed., Longman, New York, p. 1111. 1975.

[22] H. M. Monfared, O. Pouralimardan and C. Janiak. Synthesis and spectral characterization of hydrazone Schiff bases derived from 2,4-dinitrophenylhydrazine. Crystal structure of salicylaldehyde-2,4-dinitrophenylhydrazone. Z. Naturforsch, 62b. 717-720. 2007.

[23] S. Abdussalam, A. Norfarhah and A. R. Ismail. $\square$-bromoacetohpenone-2,4-dinitrophenylhydrazine. Acta Cryst. E. E65, o1221. 2009.

[24] S. Abdussalam, A. Norfarhah and A. R. Ismail. 4-(dimethylamino)benzal-dehyde 4-ethylthiosemicabazone. Acta Cryst. E64. o2353. 2008.

[25] B. Karlberg and G.E Pacey. Flow injection analysis, a practical guide. Elsevier Science Publishers, Amsterdam. (1989).

[26] V. Chis, S. Filip, V., A. Micla us, A. P1^rna u, C. Ta na selia, V. Alma s, and M. Vasilescu. Vibrational spectroscopy and theoretical studies on 2, 4-dinitrophenylhydrazine. Journal of Molecular Structure. 744-747. 363-368. 2005.

[27] E. Mariotti and M. Mascini. Determination of extra virgin olive oil acidity by FIA-titration. Food Chemistry. 73. 235-238. 2001.

[28] P.G. Nouros, C.A. Georgiou and M.G. Polissiou. Automated flow injection spectrophotometric non-aqueous titrimetric determination of the free fatty acid content of olive oil. Analytica Chimica Acta. 351. 291-297. 1997. 